\title{
Identification of Crop Disease using Augmented Reality-based Mobile App for Indian Farmers: A Prototype
}

\author{
Shrikant Salve \\ MIT Academy of Engineering, Pune, India \\ shrikantsalve@gmail.com
}

\begin{abstract}
In India agriculture provides employment for more than 50 percent of population and it also contributes about 18 percent of the total gross domestic product (GDP). The relevant and on time information is crucial for farmers to make effective decisions. Due to large failure rate in current agriculture in India many farmers are committing suicide. To empower the farmers it is imperative to incorporate right approach to provide agriculture information. So, it is important to increase the level of agriculture development making use of information communication technology (ICT). Several research have been done for development of mobile-based technologies for farmers like use of IoT for field monitoring and irrigation, Krishi Ville, AgroTIC and many more. Therefore, we have proposed a prototype of Augmented Reality-based mobile application to detect of crop diseases for farmers. This mobile-based application uses mobile camera to detect the crop disease and display name of crop on the mobile screen itself. The farmer will able to identify the crop disease immediately using his smart phone.
\end{abstract}

\section{Keywords}

Augmented Reality $\cdot$ Crop Disease $\cdot$ Farmer

How to cite this book chapter:

Salve, S. 2020. Identification of Crop Disease using Augmented Reality-based Mobile App for Indian Farmers: A Prototype. In: Loizides, F., Winckler, M., Chatterjee, U., Abdelnour-Nocera, J. and Parmaxi, A. (eds.) Human Computer Interaction and Emerging Technologies: Adjunct Proceedings from the INTERACT 2019 Workshops. Pp. 169-174. Cardiff: Cardiff University Press. DOI: https://doi.org/10.18573/ book3.v. License: CC-BY 4.0. 


\section{Introduction}

Agriculture is important sector of Indian economy and also it is the largest livelihood provider. The agriculture provides employment for more than 50 percent of population and it also contributes about 18 percent of the total gross domestic product (GDP) [1]. It is important to increase the level of agriculture development making use of information communication technology (ICT) like smartphones, cloud computing, big data, Augmented Reality, Internet of Things (IoT) to support the implementation of accuracy, improve crops and their management in agriculture sector.

Augmented Reality (AR) technology provides an interactive experience of a real world environment where the objects that reside in the real-world are 'augmented' by computer-generated perceptual information [2]. This technology can be used to support agriculture for Indian farmers those who uses smart phones. Currently there are various methods used by farmers to identify the crop disease like taking help from farmer friend, pesticide shop person, expert advice from agriculture officer or scientist or agronomist. But, neither all farmers have access to these experts nor these experts are always available. Also, it is inconvenient for farmers because most of the time these helps can take time to reach the farmers.

In this paper we have proposed a AR-based method to identify the diseases on crop. This technique uses mobile camera to view the crop disease. The crop leaf image capture through camera is matches with the online database of crop disease. Accordingly prediction of disease and preventive measure provided on the mobile screen itself. Now a days majority of farmers uses smart phone [3], this crop disease prediction mechanism through mobile app using AR technology would be convenient and easily available for the farmers.

\section{Use of ICT in Agriculture}

We have visited several villages near by Pune city, to investigate the problems related to farming. It has been observed that many farmers use smart phones to get help/information related to farming like through social networking (eg. WhatsApp, Facebook etc.), whether condition, market rates etc. We have also studied several literatures focusing on the use of ICT for farming which are stated below,

Rao and Sridhar [4] have proposed a smart agriculture project. They have developed Internet of Things (IoT)-based crop-field monitoring and automation irrigation system for farmers in India. This system generates reports on crop growth and irrigation decision support system. This kind of study would help farmers to make right decisions in farming. GappaGoshti ${ }^{T M}$ [5] is a mobilebased app developed by TCS Innovation Lab team for rural Indian farmers. It uses AR technology to recognize the insects on the crop. Some mobile-based applications available for agriculture but majority of them are proposed by Government of India and few are non-government like Kisansuvidha, Pusakrishi, 
IFFCO kisan, Agrimarket, Crop insurance, Farm-o-pedia, Bhuvan Hailstorm [6], Agri App, Iffco Kisan App, Agri Media Video App, FarmBee-RML Farmer, Kisan Yojana [7] and many more. Krishi Ville [8] is one the Android-based application developed for Indian farmers. This mobile-based application provides agriculture related updates like different agriculture commodities, weather forecast and agriculture news. Another study proposed by Ganesan et. al. [9], they have developed multimedia agricultural advisory system (MAAS) tool which is easy to understand and user-friendly for Indian farmers so as to bridges information gaps in farmer's field. MAAS is call center like interface where farmers asked their queries to be resolved by experts providing personalized information on farmer's dashboard. In this system farmers can also upload images of disease attacked plant using their mobile phone. But this system does provide the immediate solution to the farmers query especially problem on crop/plant disease which needs immediate remedy. The same way to increase the productivity of Colombian farmers, Camacho and Arguello [10] proposed a social networking application for farmers called as AgroTIC. It consist of four modules like Communication for farmer to farmer, farmer to expert communication, Image processing and estimation of visible vegetation indices, production and marketing module. This is excellent study helped us to understand different aspects of problems occurred in agriculture. This paper also gives the idea of vegetation indices method which can be used to identify the crop disease using image processing.

\section{Methodology}

This project has been part of Unnat Bharat Abhiyan (UBA) [11] being carried out in Maharashtra Institute of Technology AOE Pune. UBA Scheme is proposed by Govt. of India for the betterment of India villages by providing engineering solutions to their problems. During our initial visit to several villages around Pune city and interaction with people especially farmers, we have observed several problems related to farming. We found that identification of crop disease is the major issue for the farmers. The literature study found that plenty of research has been done on agriculture sector. The study also shows that especially the mobile-based techniques have been implemented to support farmers. Therefore, we are developing mobile-based augmented reality application for prediction of crop disease. The below section explains the detailed methodology including participants, tools, procedure.

Participants. Twenty participants were voluntarily involved in this study from two villages like Nirgudi, Dhanore located nearby Pune city. The Figure-1 depicts the students conducting ethnographic study of farmers.

Tool and Procedure. The questionnaire has been prepared for conduction of interview with the farmers. This includes demographic information and 
questions related to how farmers deal with crop disease, use of technology for farming etc. The sample questionnaire is depicted in Figure 2.

We have developed a prototype of mobile-based application which uses augmented reality technology. This tool/app uses mobile camera to capture the image of infected crop leaf. The crop leaf image is matches with the online database of crop disease. Accordingly prediction of disease and preventive measure provided on the mobile screen itself. The following Figure 3 gives screen-shots of the developed application.

The drawback of this system is that mobile application needs to be tested by actual farmers. Also, the user interface of the applications is not in local language.
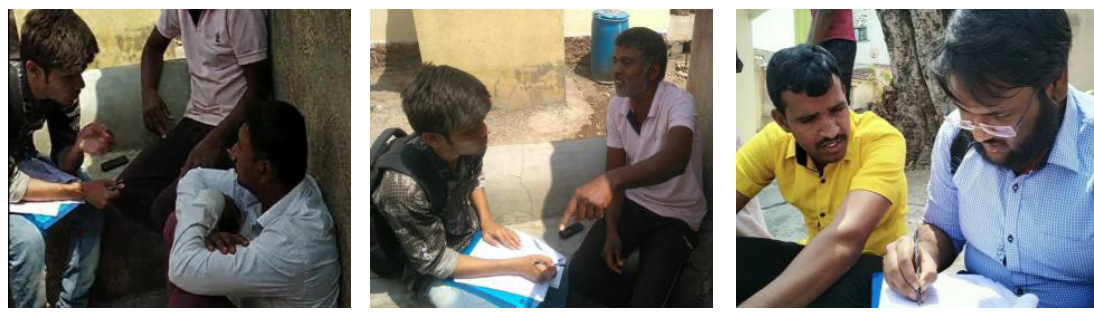

Fig. 1: Interaction with Farmers at Nirgudi and Dhanore Village.

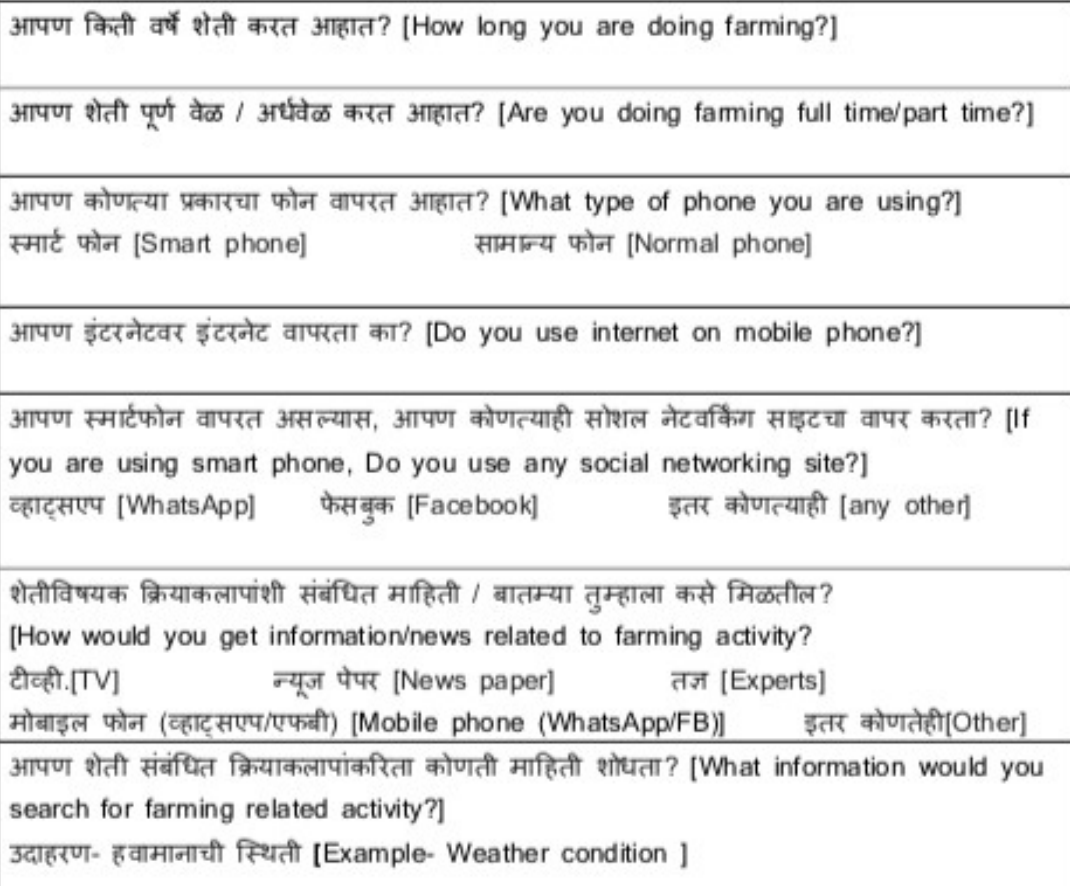

Fig. 2: Questionnaire used for data collection. 

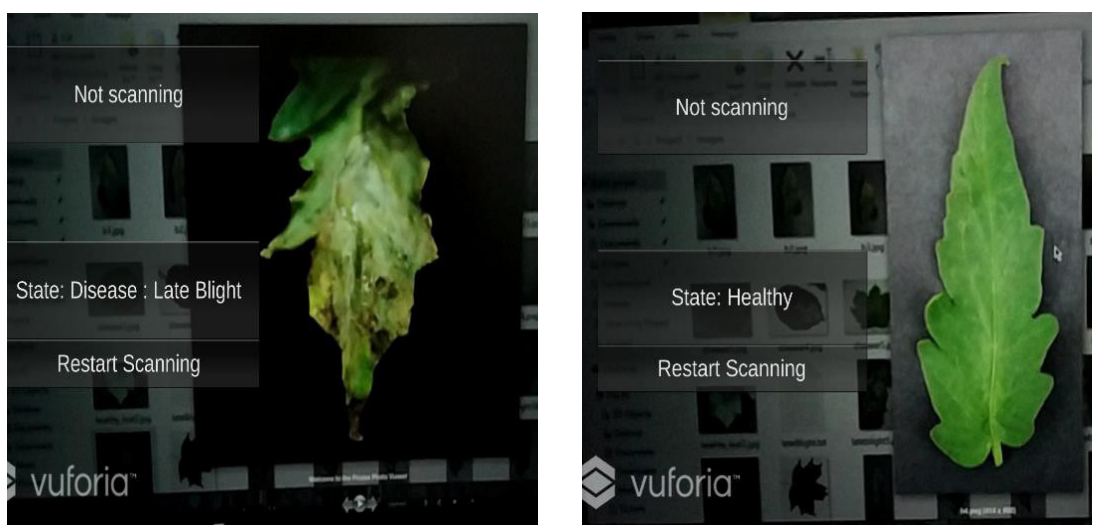

Fig. 3: The screen-shot of AR-based mobile app (a) Screen-shot of infected leaf

(b) Screen-shot of non-infected or healthy leaf.

\section{Conclusion}

We have implemented the prototype of AR-based mobile application which successfully identifies the disease on the crop leaf. We have used image of the infected crop leaf as marker. The farmer will able to identify the crop disease immediately using his smart phone. In future we are planning to use the actual crop leaf as marker.

\section{Acknowledgements}

I am thankful to Mr. Omkar Pawar, Mr. Rahul Sahoo and Mr. Rupesh More, all are SY BTech students at MIT AOE, who helped in ethnographic study. I also appreciate the farmers who voluntarily participated in this research activity.

\section{References}

1. Madhusudhan, L.: Agriculture Role on Indian Economy. Bus Eco J 6(4), 176 (2015). doi: https://doi.org/10.4172/2151-6219.1000176

2. Azuma, R.T.: A Survey of Augmented Reality. Presence: Teleoperators and Virtual Environments 6(4), 355-385 (1997).

3. Mobile Usage In Agriculture \& Healthcare Sector In India [Report], https://www.trak.in, last accessed 2019/05/15.

4. Rao, R. N., Sridhar, B.: IoT based smart crop-field monitoring and automation irrigation system. In: Proceedings of 2nd International Conference on Inventive Systems and Control (ICISC), pp. 478-483. Coimbatore (2018) doi: 10.1109/ICISC.2018.8399118 
5. Nigam, A., Kabra, P., Doke, P.: Augmented Reality in agriculture. IEEE 7th International Conference on Wireless and Mobile Computing, Networking and Communications (WiMob), Wuhan, pp. 445-448 (2011).

6. Kailash: A study on use of mobile phone technology (smart phone) by the farmers of Nagapur district in Rajasthan. M.Sc. Thesis at Institute of Agricultural Sciences, Banaras Hindu University, Varanacy, India (2016).

7. Ahmed, Pasha, R., Prathap, V., Pasha, A., Kumari, D., Faraz: Survey on Precision Farming using Mobile Applications. Global Journal of Computer Science and Technology, (2019).

8. Singhal, M., Verma, K., Shukla A.: Krishi Ville Android based solution for Indian agriculture. Fifth IEEE International Conference on Advanced Telecommunication Systems and Networks (ANTS), Bangalore, pp. 1-5 (2011). doi: https://doi.org/10.1109/ANTS.2011.6163685

9. Ganesan, M., Karthikeyan, K., Prashant, S., Umadikar, J.: Use of mobile multimedia agricultural advisory systems by Indian farmers: Results of a survey. Journal of Agricultural Extension and Rural Development, 5(4), 89-99 (2013).

10. Camacho, A., Arguello, H.: Smartphone-based application for agricultural remote technical assistance and estimation of visible vegetation index to farmer in Colombia: AgroTIC. Proc. SPIE 10783, Remote Sensing for Agriculture, Ecosystems, and Hydrology XX, 107830K (2018).

11. Unnat Bharat Abhiyaan Homepage. http://unnatbharatabhiyan.gov.in.last accessed 2019/05/15. 